\title{
11
}

\section{Erratum to: "Police Chiefs in the UK: Politicians, HR Managers or Cops?"}

\section{Mark Roycroft}

\author{
(C) The Author(s) 2017 \\ M. Roycroft, Police Chiefs in the UK, \\ DOI 10.1007/978-3-319-44105-4_11
}

Unfortunately, some typos have been incorporated throughout the book and are corrected now.

\section{Glossary now includes:}

CJ system Criminal Justice system.

PSNI Police Service of Northern Ireland

OPC Office of Professional Conduct

\section{Chapter 1}

Page 3: 3rd sentence from the bottom, it is page 18 not 16.

P5: Missing ? In 2nd para after HR managers or cops.

P12: extra "of" in New model of Model of Policing for 2016 at bottom of page

P13: missing "and that" para 2 after " accurate financial position"

P19: CJ system should read Criminal justice (CJ) system

The updated original online version for the book can be found at DOI 10.1007/978-3-319-44105-4

(C) The Author(s) 2017 


\section{Chapter 2}

P25: missing comma, line 26 after "public sector collaboration in local policing, while RCC 5 then comma before an and on next line after "PCSOs, and"

P 28: line 4 missing phrase "notion that the UK"

P29: line19 extra "the" after "of the 32,500 officers in London (the?) Just 2740 , the metropolitan police service should be in capitals.

P 30: 5 th line from bottom full stop after police officers. While CC40 "there should be a comma rather than a full stop.

\section{Chapter 4}

P41: 10th line from the bottom The NADGA ( see p87) should read P 198 P43: 6 th line after end of table 3.1 there is a P45: Title of table 3.2 should read Benefits and concerns associated with a blended model of private and public policing.

\section{Chapter 5}

p80: bottom line after Contest strategy insert P80 and delete p78 P82: after EMSOU insert (East Midlands Special Operations Unit)

\section{Chapter 6}

P89: Please insert comma after Chief (line ${ }^{*}$ ) and after those interviewed. P90: Misspelling of Commissioner in sub title but spelt correctly in text P91: Line 12 please insert (see page 112) after Social Responsibility Act 2011. P92: In the table please correct

- The Police Act of 1946 this should read The Police Act 1946 led to the creation of 133 separate forces in England and Wales

- Then in date order it should include 1948 Formation of ACPO which led to the creation of the present day 43 Forces in England and Wales.

- Move Lord Laming's report to 2003 so below introduction of PCSOs in 2002

- Then 2012 introduction of Police and Crime commissioners (in capitals) and elections held in November 2012 
P97: Line 20 delete Cumbria and include Cleveland.

P99: line 9 Chief constable Posts should read Chief Constable posts

6th line from the bottom should be "who earn an average of" delete the $s$

P98: delete line11 ( that starts it should also be noted to line 19 it should read Police Regulations 2003 (Regulation 11) was amended by Home Office Circular 021/2012 and it removed the experience requirement which had previously stated that no person shall be appointed as chief constable of a police force unless for a period of not less than two years he or she has held the rank of assistant chief constable (or commander in the Metropolitan Police Service or the City of London police force) or above in some other police force. This no longer applies. Manchester Evening News....

P100: bottom line after another post should read. As stated we now have... p101: 3rd line from bottom delete Cumbria and include Cleveland

P103: line 16 should read" provide more influence delete "be"

P104: Diversity of Chief Constable should have a cross reference to P 16 and vice versa.

P105: 2nd line remove bracket before CC7 and insert comma between in and CC7

Line 5 remove one "along with" as this is repeated

P107: the same quote is mentioned twice by CC21 the sub Para at the end of the page should be deleted.

P109: apostrophe line 2 should read Chief s

P110: 11th line from the bottom should have a comma and not a full stop after social events.

P112: line 15 after "I have not needed it," add "it is" before "wavering by Government"

P115: move quotation mark 9th line from the bottom from after (PCC18) to after defensive.

P117: 6 th line from bottom semi colon after (1978 p290

\section{Chapter 6 and 7}

The page headings on P 2 of each Chapter run out i.e. the words Constables and Commissioners are missing. 
P119: should read Lord Wasserman, the government, policing and criminal justice advisor, in a House of Lords speech (1/11/12) "In short, the successful PCC will be the leader of a community-wide effort aimed at achieving more effective local policing and safer community "delete existing quote.

P120: 7th line from the bottom delete "The proposed mayors will also be PCCs and insert" The Metro Mayors elected in May 2017 will be PCCs as per the London mayoral model as per MOPAC above. 11 th line from the bottom after 4 years, initially for 2 terms but they can now serve for an unlimited period.

P122: should read the composition of the PCCs (at the time of the research) politically

P125: line 9 from the bottom insert (see P 112) after (the power to dismiss a PC)

P126: delete "Sir Peter Fahy 22 October 2015 Police Professional"

P127: insert comma after NHS, and before as well as Last line should read and worked rather than work

P128: line 4 deletes 2015 and insert 2014

Sue Mountstevens,surname should be all one word

P130: line 17 after Chief executive insert semi colon before "for instance PCC 8 commented"

Line 19 insert a before "unique political and constitutional position"

P132: comma before and 4 th line from the bottom

P135: 6 th line from the bottom insert comma after "power corrupts" 4th line from the bottom should read "a single individual"

P136: insert comma after "learn and listen"

P137: should read 11th line from the bottom after IPCC see Chap 9 rather than Chap 8.

P138: line 12 from the bottom should read over Rotherham than in

P141: line18 missing words "the" before electorate and should after it, the line should be "the electorate should decide"

Line 4 delete July and insert June

Line 5 after Cusp should read (see Tone from the Top)

Line 22 after D/V comma should be inserted.

Line 23 after me should read "they have limited teeth"

Line 29 insert "at end of quote 
P143: line 14 from bottom comma after PCC and word while in place of and after $£ 1,500$ a year

P144: line10 comma needed after PCC10,

P146: comma after Fire and Rescue. Professor Rodgers not a full stop, 12 th line from the bottom

P156: line 5 from bottom "around" should be included before the word criminality

Line12 insert comma after engagement and before they will not get involved

p157: line20 with them delete issues

P166: Home Affairs Select Committee report on PCCs should be indexed and under reports p 217

P167: 2nd para should have Reshaping policing for the public in italics and or quotation marks, it has a full stop after public but should continue to line 5 of that paragraph

P176: Office of Police Conduct not included in index on P222

P179: line5 should read budget cuts in lower case

P181: line 14 should have (see P179) after i.e. Humberside

P182: quote on line 6 should be in inverted commas and comma missing on line 10 between Budget and the HMIC Inspectors

P183: line 8 after HMIC the word there appears it should be deleted.

Missing comma after important, line 12,

Line16 should read HMIC grading (seeP179)

P184: comma after organisation line 13. And line 23 commas after issues and before essential and missing "it is"

P185: comma after policing, he is seen as a public negotiator 3rd line from the bottom and should have (Sir Tom Winsor) in brackets after he.

P186: line 8 word and split into 2 para

P187: comma missing line 4 after shoes

P191: line 8 should read see Chap3 not Chap7 about funding

P200: 10 th line from bottom delete $s$ after APCC.

P194: 14 th line from the bottom should read the demands of victims p198: 11th line from the top should read "operational matters and to create more efficient safeguarding and preventative measures" P200: line 7 from the top the 3 Es should all be in capitals 
P201: 6 th line from bottom should read affect not effect

P215: Committee on Standards in Public life should then read in italics Tone from the Top, then brackets (June 2015)

Add Police Service. New governance strategy House of Lords Hansard 1/11/12 publications. Parliament. uk Lord Wassermann's speech

P216: Neyroud report should read(2010)

P217: add 7/3/16 Sir Tom Winsor Police talent scared off by elected officials.

7/3/16 Muir, H.

\section{Index}

p223: Martin Underhill is Dorset PCC not Devon and Cornwall

P223: Sawyer, Shaun is CC of Devon and Cornwall police

\section{Cover}

Rear cover should read Dr Mark Roycroft UHI and during his career dealt with major investigations, police intelligence and Fulbright scholar. Add p 215 to Wasserman, G entry

\section{Amendments to Police chiefs Book}

\section{List of abbreviations}

Please add;

- BAME: Black and Ethnic Minorities

- CJ system: Criminal Justice system

- PEEL: Police effectiveness, efficiency and legitimacy HMIC programme.

\section{All tables can we please insert columns}

\section{Chapter 1}

P16: please cross reference to page 104 and vice versa

P19: the CJ system should read Criminal Justice system

\section{Chapter 2}

P24: line 2 After "We can't do everything, insert comma

P29: 3rd line 19 please put Metropolitan Police Service in capitals.

\section{Index}

Please add;

College of Policing Estimating Demand report to p214 
P 32: Please add "Waddington, P. A. J. (2003) in Newburn, T. (Ed.), A Handbook of Policing, pp 394-421" to references

P35: line 4 after "on crowd dispersal add comma

\section{Chapter 3}

P40: line 11 please add a before central government grant

P41: line 5 delete who

P45: Title of Table 23.2 should read Benefits and concerns associated with private/public policing

P45: insert (2015) after Institute for Fiscal Studies on last line P47: third para,line 3 full stop after disquiet then capital $M$ for many P49: second para should start "The then Policing Minister Mike Penning

\section{Chapter 5}

P64: after ROCU second para should read P 66 rather than p70

P65: line 10 should read Education,Engineering and Enforcement.

P70: last para should read Under the then Chief Constable Creedon

P83: end of the first para. The Manchester bombings and two attacks in London in 2017 illustrate the need for the British Police to provide a timely response but to provide reassurance and investigative skills.

\section{Chapter 6}

P90: Chiefs in capital end of first para

P91: end of second para insert (P112) after Social Responsibility Act 2011

P91: semi colon after 3rd para He said

P92: please put time line in date order

Police Act 1946 should read Police Act 1964

Lord Lamings report should be put in order

2012 should read Introduction of the Police and Crime

Commissioners in capitals

P95: bottom line,"elected" should be in lower case

P107: 2nd pars comma after drop in the ocean

P115: Please insert What the Police Crime Commissioners (PCCs) PCCs think of Chief Constables (CCs)

Full stop after Chief Constable line 3 and delete but.

Line 8 missing word "the" before times.

P118: line 4 missing date should read (2005:p257)

P120: delete A PCCs term of office is 4 years with a maximum of 2 years 
P122: The Background of PCCs should read

"The political composition of the PCCs (at the time of the research) was made up of ...

P124: should read "What is the remit of PCCs?

P125: Second apara should read PCCs have under the 2011 Act (see p112)

P127: should read 6 lines from the bottom should read victims needs not crime needs.

P129: should have " before and after "The Pioneers:Police and cRime Commissioners, 1 year on "

P131: top line apostrophe PCC23's

P132: Sir tom Winsor to index

P135: CC instaed of PCC line 12

P136: PCC21 should read CC21

P141: missing " at the end of para 2

3rd 2 nd last sentence should read the PCP stated they had little faith ...

P142: should read top line: realignment, Police and Crime Panels need a redesign."

P143: New Statesmen to Index

P144: 2nd sentence Facing the Future in capitals

Dealing with Police culture comma after second line after PCC10

\section{Chapter 8}

P154: CC36 delete they in line 3

P157: 3rd para 4 CC should read 4 CCs'

Cyber crime in capitals line 10 para 3 delete repeat and full stop and it

P159: quotation marks on collaboration 2nd paar

P160: should read "fewer but larger forces was the view after the debate"

P162: should read Finance not refinance,line 8

4 th para delete "explain rewrite ability and

P163: insert extra line after Training para "The College of Policing are working with Higher Education institutions around the Police Education Quality Framework (PEQF). This will involve all police officers being educated to degree level. Please ensure it fits on the page. 
P166: comma after collaboration 3rd para

P167: Reshaping policing for the public in italics

P168: Insert on last line of summary. The layering of Police functions was discussed

\section{Chapter 9}

P173: remove / after mindfulness 3rd para,insert a comma instead

P176: Please index the Policing Ombudsman Office of Northern Ireland Insert Police Investigations and Review Commissioner (PIRC) Scotland in place of PIRC Scotland

P178: Insert Her Majesty's Inspectorate of Constabulary (HMIC) in place of HMIC

P179: Insert the Police effectiveness, efficiency and legitimacy (PEEL) HMIC programme in place of PEEL end of second para.

P180: missing word end of first para should read This was a common issue raised by interviewees about who held the accountability organisations to account.

P182: 2 nd para missing word: after (PCC30) and it had not contributed Insert What the CCs and PCCs said about the HMIC, replace the existing headline

P183: delete their after HMIC 2nd para, so should read HMIC reports and comments

P184: delete What the PCCS say about the HMIC,please ensure it does not affect the page number

P185: insert full stop after confidence in policing 2nd para

PCC21: para insert a comma after written report

P186: replace an $\mathrm{d}$ with and, end of first para

P187: 3rd para disconnect should be in lower case

P188: top line remove making it much more so the line reads making the reports more proximate to the inspection

\section{Chapter 10}

P193: replace COPACC with $\mathrm{CoPaCC}$

P194: 2nd para replace All three policing oversight bodies with All the policing oversight bodies

P197: delte Project Aurora in Notts

P200: please put all 3 Es in capitals 
Put comma after local neighbourhood teams and before NADGA report (2015)

Insert The UK now has six Metro Mayors after elections in 2017 that bring the UK closer to an American Mayoral system. These Mayors are also Police and Crime Commissioners. in place of The UK does not have an American Governor or Mayor type system as yet.

\section{References}

P216: delete lines 11 and 12 after bust that starts IPCC as it is included in the next line

P216: after NDAGA insert

P216: delete Neyroud report insert (2-10)

P220: Index place HASC report on PCCs 5/5/15 P 166

P222: Insert Posen review P143 